\title{
Reduced Cardiovascular Mortality Associated with Early Vascular Access Placement in Elderly Patients with Chronic Kidney Disease
}

\author{
Timmy Lee ${ }^{a, b}$ Mae Thamer ${ }^{c}$ Qian Zhang ${ }^{c}$ Yi Zhang ${ }^{c}$ Michael Allon ${ }^{a}$ \\ ${ }^{a}$ Department of Medicine, Division of Nephrology, University of Alabama at Birmingham, and ${ }^{\text {b } V e t e r a n s ~ A f f a i r s ~}$ \\ Medical Center, Birmingham, Ala., and ' Medical Technology and Practice Patterns Institute, Bethesda, Md., USA
}

\section{Key Words}

End-stage renal disease - Hemodialysis - Vascular access .

Arteriovenous fistula $\cdot$ Arteriovenous graft

\begin{abstract}
Background: Elderly patients with cardiovascular comorbidities are more likely to die before progressing to the need for undergoing hemodialysis; so deferring their predialysis vascular access (VA) surgery has been suggested. However, recent declines in cardiovascular mortality in the US population may have changed this consideration. We assessed whether there has been a parallel decrease in cardiovascular comorbidity in elderly chronic kidney disease (CKD) patients undergoing predialysis access surgery, and whether this impacted clinical outcomes after access creation and cardiovascular events after hemodialysis initiation. Methods: We identified 3,418 elderly patients undergoing predialysis VA creation from 2004 to 2009, divided them into 3 time cohorts (2004-2005, 2006-2007 and 2008-2009), and assessed their clinical outcomes during 2 years of follow-up. Results: There was a progressive decrease in patients with history of peripheral vascular disease (from 66.5 to $59.7 \%, p<0.005$ ), heart failure (from 47.0 to $35.8 \%, \mathrm{p}<0.005$ ), and myocardial infarction (from 6.5 to $3.3 \%, p<0.001$ ) from 2004 to 2009 . Death before hemodialysis decreased from 17.5 to $12.6 \%$,
\end{abstract}

survival without hemodialysis increased from 14.5 to $19.0 \%$, and hemodialysis initiation remained constant at $\sim 68 \%(\mathrm{p}<$ 0.001 ). The incidence of death or cardiovascular event in the first year of hemodialysis decreased from 2004-2005 to 2008-2009 (HR 0.83, 95\% Cl 0.69-0.99; $p=0.04$ ). Conclusion: In the context of a changing population from 2004 to 2009, a progressive decrease in cardiovascular comorbidities in elderly CKD patients undergoing predialysis VA surgery was associated with a decrease in death before hemodialysis and cardiovascular events after starting hemodialysis. These insights should be translated into more thoughtful consideration as to which elderly patients should undergo predialysis access surgery.

(c) 2016 S. Karger AG, Basel

\section{Introduction}

A majority $(\sim 70 \%)$ of elderly US patients with advanced chronic kidney disease (CKD) receiving a predialysis permanent vascular access (VA) initiate hemodi-

This manuscript was presented in abstract form at the 2015 American Society of Nephrology Kidney Week, San Diego, Calif., USA, November 3-8.

\section{KARGER}

E-Mail karger@karger.com

www.karger.com/ajn
(C) 2016 S. Karger AG, Basel

0250-8095/16/0435-0334\$39.50/0
Associate Prof Timmy Lee, MD, MSPH, FACP, FASN

Department of Medicine, Division of Nephrology

University of Alabama at Birmingham

Zeigler Research Building 524, 1720 2nd Ave South, Birmingham, AL 35294-0007 (USA) E-Mail txlee@uab.edu 
alysis within 2 years of access surgery, suggesting that nephrologists are appropriately incorporating patient age in determining the optimal timing of referral of elderly patients for predialysis permanent VA placement [1]. Because elderly patients with high cardiovascular comorbidity are also more likely to die before the initiation of dialysis, deferring VA creation in elderly patients with cardiovascular comorbidity has been suggested. Deaths in patients with CKD are largely driven by cardiovascular comorbidity $[2,3]$. However, in the last decade between 2000 and 2010, there has been a substantial decline in cardiovascular mortality observed in both the general adult population and in the hemodialysis population in the United States $[4,5]$. The goal of the current study was to investigate whether there was a parallel improvement in cardiovascular comorbidity among a select group of elderly patients with CKD undergoing predialysis access surgery, and whether this trend affected the likelihood of dying before initiating dialysis, survival without initiating dialysis, or initiating dialysis during 2 years of follow-up after VA surgery. To evaluate these questions, we used a large representative US population of elderly CKD patients undergoing predialysis VA creation between 2004 and 2009, and divided them into 3 time cohorts (20042005, 2006-2007 and 2008-2009). For each temporal cohort, we assessed the cardiovascular comorbidities and cardiovascular events prior to VA surgery, as well as cardiovascular events occurring in the first year after dialysis initiation.

\section{Methods}

Data Sources and Study Population

A waiver from the University of Alabama at Birmingham Investigational Review Board was obtained before initiating data analysis. Patient consent was not obtained for this study, as all information utilized for this study were from national administrative claims data from a random sample of 5\% Medicare patients with CKD and data from the United States Renal Data System (USRDS). Center for Medicare and Medicaid Services rules allow for the release of limited data sets with a data use agreement executed with the USRDS coordinating center. Data source and patient exclusion criteria were described in detail in our previous paper [1]. To summarize, we identified 3,418 Medicare patients aged 70 and older with an incident VA created before dialysis between January 1, 2004 and December 31, 2009 from using a Medicare 5\% sample CKD-based cohort [1]. Our cohort consisted of patients 70 years and older in order to allow for a 5 -year baseline before the index date (similar to one used by Oliver et al. [6]) to ensure a first predialysis VA surgery and to collect complete severity of illness and comorbidity information. Specifically, the CKD patient, physician/supplier, and institutional claims were used to obtain hospi- talization, surgery, comorbidities, and outpatient encounters. A 5 -year baseline prior to the index date (similar to one used by Oliver et al. [6]) was used to ensure an incident VA surgery and to collect severity of illness and comorbidity information. Patients were followed from incident VA creation until initiation of dialysis, death or end of 2-year follow-up.

\section{Variables of Interest}

Patient demographics (age, gender and race) were determined from CKD-based cohort patient file. Comorbidities were determined by 1 inpatient diagnosis code (either primary or secondary) and/or 2 outpatient diagnosis codes in the year prior to the index date and included diabetes, cancer, ischemic heart disease, chronic obstructive pulmonary disease, peripheral vascular disease (PVD), cerebral vascular disease, depression, dementia, and amputation. Cardiovascular comorbidities (e.g. stroke, myocardial infarction (MI) and congestive heart failure (CHF)) were identified based on a primary reason for hospitalization during the baseline year. Comorbidities were selected based upon published literature indicating a substantial influence on mortality among late stage CKD patients $[7,8]$. We used a comorbidity index developed and validated for dialysis patients, which outperformed the more widely used Charlson comorbidity index in both predictive ability and inference [9-11].

\section{Statistical Analysis}

The baseline demographic and clinical characteristics of 3 temporal cohorts (2004-2005, 2006-2007 and 2008-2009) were summarized as frequency (percentage) for categorical data and mean \pm $\mathrm{SD}$ for numeric data. To evaluate potential differences in medical care received by patients across the 3 time periods, we calculated outpatient physician and nephrologist visits and hospitalizations per patient-time. We further linked the 3 temporal cohorts of CKD patients to USRDS Medical Evidence Form to identify patients who initiated dialysis within 2 years of VA creation. These patients were followed from dialysis initiation for 1 year to calculate a composite end-point of death or cardiovascular events, or the end of follow-up. Patients' acute cardiovascular events including $\mathrm{CHF}$, MI, and stroke were obtained from USRDS institutional claims by using International Classification of Disease- 9 codes as follows: CHF ('402x1', '404x1', '404x3', '422', '425', '428', and 'V421'), MI ('410'), and stroke ('430' to '434'). Survival at 180 and 360 days after dialysis initiation was examined using Kaplan-Meier survival curves and compared across 3 time periods. A composite endpoint of a cardiovascular event or mortality, whichever came first, was also calculated. All the analyses were conducted by SAS version 9.2.

\section{Results}

\section{Temporal Trends in Patient Characteristics and Comorbidities}

During the 6-year period between January 1, 2004 and December 31, 2009, 3,418 elderly (age $\geq 70$ ) CKD patients from the 5\% Medicare sample received an AVF or AVG before initiating dialysis (table 1). The mean age of study patients was 78.0. A majority of patients were male (54.0\%) 
Table 1. Temporal trend of demographics and comorbidities in elderly patients with CKD after first VA insertion

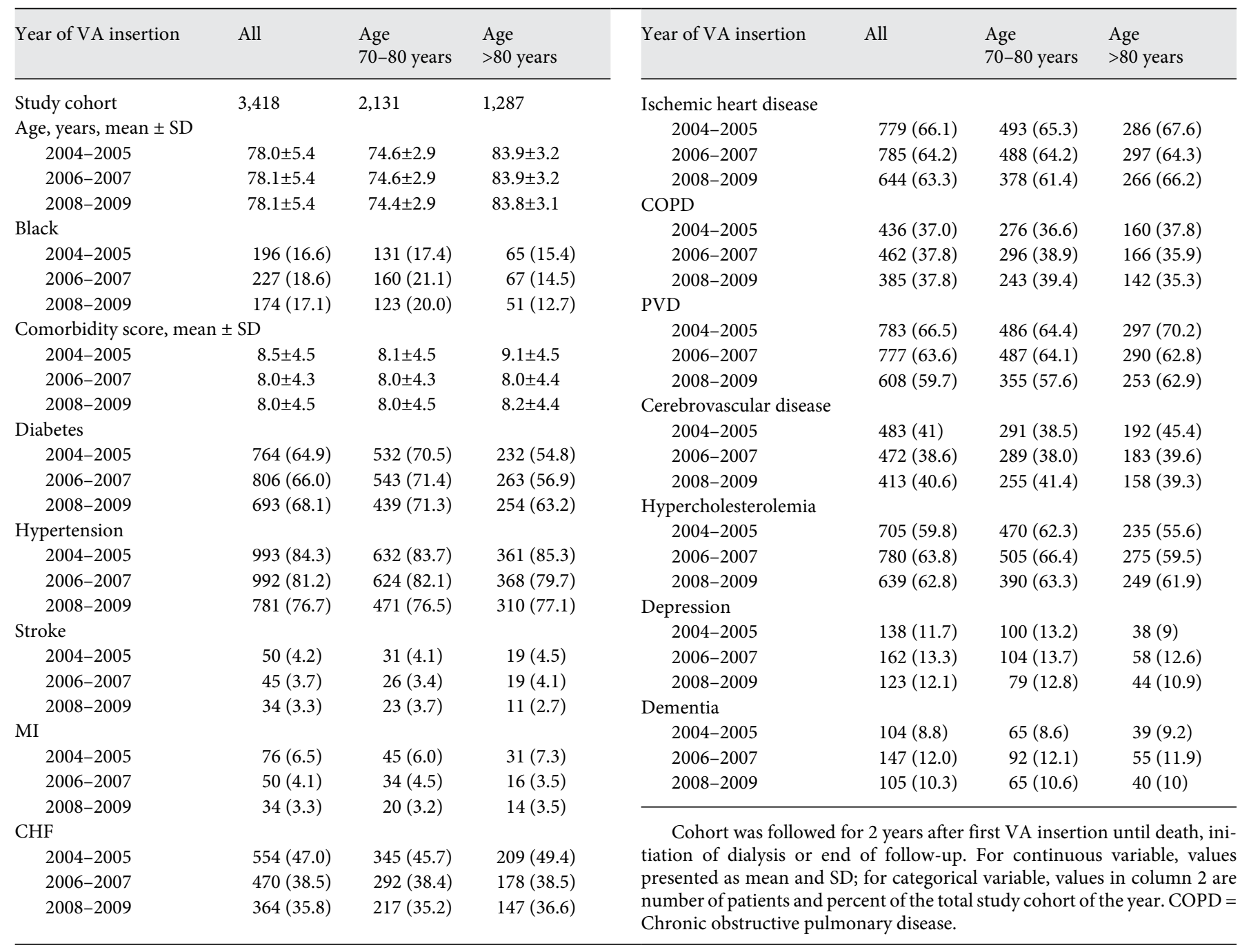

and white (74.7\%), and a substantial proportion had diabetes $(66.2 \%)$, ischemic heart disease (64.6\%), PVD (63.4\%) and CHF (40.6\%). Among elderly patients who received a predialysis $\mathrm{VA}$, there was a progressive decrease in patients with history of PVD (from 66.5 to $59.7 \%$, p < 0.005), $\mathrm{CHF}$ (from 47.0 to $35.8 \%, \mathrm{p}<0.005$ ) and $\mathrm{MI}$ (from 6.5 to $3.3 \%, \mathrm{p}<0.001$ ) between the 3 time cohorts (20042005, 2006-2007 and 2008-2009). The decrease in cardiovascular comorbidities in the 3 time periods was greater in patients age $>80$ than in those aged 70-80. Specifically, the relative decrease in stroke (40 vs. $10 \%$ ), MI (52 vs. $47 \%$ ) and CHF (26 vs. $23 \%$ ) and comorbidity score (10 vs. $1 \%)$ was consistently greater in the older patient cohort (table 1a). All other demographics and comorbidities were similar between the 3 time cohorts (table 1).
Temporal Trends in Clinical Outcomes before Initiation of Hemodialysis

During the 3 consecutive time periods (2004-2005, 2006-2007 and 2008-2009), the proportion of elderly patients dying before initiating hemodialysis decreased from 17.5 to $12.6 \%$, the proportion surviving without hemodialysis increased from 14.5 to $19.0 \%$ and the proportion initiating hemodialysis remained constant at $\sim 68 \%$ $(\mathrm{p}<0.001$; table 2$)$. We also evaluated rates of hospitalization and outpatient visits per patient-year among elderly CKD patients after predialysis VA was placed. Overall, there was no difference in rates of hospitalization, outpatient physician visits or nephrology visits between the 3 time cohorts (data not shown). 
Table 2. Temporal trend of clinical outcomes in elderly patients with CKD after first VA insertion stratified by year of VA insertion and by age subgroups

\begin{tabular}{llll}
\hline Cohort & $\begin{array}{l}\text { Initiated } \\
\text { dialysis } \\
\text { within } \\
2 \text { years }\end{array}$ & $\begin{array}{l}\text { Died } \\
\text { before } \\
\text { dialysis }\end{array}$ & $\begin{array}{l}\text { Survived } \\
\text { and no } \\
\text { dialysis }\end{array}$ \\
& & & \\
\hline $\begin{array}{l}\text { Full cohort }(\mathrm{n}=3,418) \\
2004-2005\end{array}$ & $801(68.0)$ & $206(17.5)$ & $171(14.5)$ \\
$2006-2007$ & $806(66.0)$ & $181(14.8)$ & $235(19.2)$ \\
$2008-2009$ & $697(68.5)$ & $128(12.6)$ & $193(19.0)$ \\
Age 70-80 years $(\mathrm{n}=2,131)$ & $522(69.1)$ & $119(15.8)$ & $114(15.1)$ \\
$2004-2005$ & $508(66.8)$ & $103(13.6)$ & $149(19.6)$ \\
$2006-2007$ & $432(70.1)$ & $65(10.6)$ & $119(19.3)$ \\
$2008-2009$ & $279(66.0)$ & $87(20.6)$ & $57(13.5)$ \\
Age $>80$ years $(\mathrm{n}=1,287)$ & $78(16.9)$ & $86(18.6)$ \\
$2004-2005$ & $298(64.5)$ & $63(15.7)$ & $74(18.4)$ \\
$2006-2007$ & $265(65.9)$ & $63(15.4)$ \\
$2008-2009$ & &
\end{tabular}

Values presented as number of patients and row percentage in parenthesis. $\mathrm{p}<0.001$ for full cohort; $\mathrm{p}=0.01$ for age $70-80$ years; $\mathrm{p}=0.11$ for age $>80$ indicating differences between all 3 time periods.

Table 3. Proportion of patients dying within 180 and 360 days after dialysis initiation, stratified by year of VA insertion and by age subgroups

\begin{tabular}{llll}
\hline Cohort & $\begin{array}{l}\text { Dialysis } \\
\text { patients, } \mathrm{n}\end{array}$ & $\begin{array}{l}\text { Death at } 180 \\
\text { days, } \mathrm{n}(\%)\end{array}$ & $\begin{array}{l}\text { Death at 360 } \\
\text { days, } \mathrm{n}(\%)\end{array}$ \\
\hline $\begin{array}{l}\text { Full cohort } \\
\text { 2004-2005 }\end{array}$ & 801 & $111(13.9)$ & $197(24.6)$ \\
$2006-2007$ & 806 & $87(10.8)$ & $177(22.0)$ \\
$2008-2009$ & 697 & $86(12.3)$ & $148(21.2)$ \\
$\begin{array}{c}\text { Age 70-80 years } \\
\text { 2004-2005 }\end{array}$ & 522 & $57(10.9)$ & $103(19.7)$ \\
$2006-2007$ & 508 & $47(9.3)$ & $100(19.7)$ \\
$2008-2009$ & 432 & $48(11.1)$ & $83(19.2)$ \\
Age >80 years & & $54(19.4)$ & $94(33.7)$ \\
$2004-2005$ & 279 & $40(13.4)$ & $77(25.8)^{*}$ \\
$2006-2007$ & 298 & $38(14.3)$ & $65(24.5)^{*}$ \\
$2008-2009$ & 265 & & \\
\hline & & & \\
\hline
\end{tabular}

Temporal Trends in Outcomes among Elderly

Patients with Predialysis VA Placement Initiating

Hemodialysis

Table 3 summarizes the mortality of elderly patients with predialysis VA placement who initiated hemodialy- sis from 2004 to 2009 . For the overall cohort, there was a nonsignificant decrease in patient mortality at 180 and 360 days after initiation of dialysis between the 3 time periods. However, mortality differences were evident when the patients were subdivided into 2 age ranges; the 1 -year mortality decreased by a nonsignificant $3 \%$ in patients aged $70-80$ years, but decreased by $27 \%$ in those $>80$ years $(\mathrm{p}<0.05)$. Between 2004-2005 and 2008-2009, the proportion of patients with a new CHF event during the first year of dialysis decreased by $28 \%$, from 10.7 to $7.7 \%$ ( $\mathrm{p}=$ 0.047 ), and the proportion with the composite endpoint of death or a new cardiovascular event (CHF, MI or cerebrovascular accident) decreased by $15 \%$, from 35.2 to $30.0 \%(\mathrm{p}=0.03)$. Finally, the cumulative incidence of death or cardiovascular event was substantially reduced from 2004-2005 to 2008-2009 (HR 0.83, 95\% CI 0.69$0.99 ; \mathrm{p}=0.04$ ) in the overall cohort (fig. 1a). When stratified by age categories 70-80 (fig. 1b) and $>80$ (fig. 1c), only age $>80$ demonstrated substantially reduced incidence of death or cardiovascular event (HR 0.74, 95\% CI $0.56-0.97 ; \mathrm{p}=0.03$ ).

\section{Discussion}

We have identified a trend over a 6-year period (from 2004 to 2009) of improving cardiovascular comorbidity among a select group of elderly CKD patients undergoing predialysis VA that was reflected in a smaller proportion of patients with a history of PVD, heart failure or MI. In our study, this trend seemed to be driven by the improved cardiovascular outcomes in patients age $>80$. To our knowledge, secular changes in cardiovascular health have not been previously reported among the $\mathrm{CKD}$ predialysis population. As one might expect, the lower cardiovascular comorbidities in this population translated into improved clinical outcomes after access creation, namely, fewer patients dying before dialysis and more patients surviving without requiring initiation of dialysis.

What might account for such a large improvement in the cardiovascular comorbidities of this population over a relatively short time period? The most likely explanation is that the improvement in cardiovascular comorbidities among elderly CKD patients undergoing predialysis access surgery simply mirrors that trend observed in the overall US population. Cardiovascular mortality declined by $30.8 \%$ from 2001 to 2011 among the general adult US population, a change that has been attributed to smoking cessation, better blood pressure control and more widespread use of statins [4]. There was a similar 


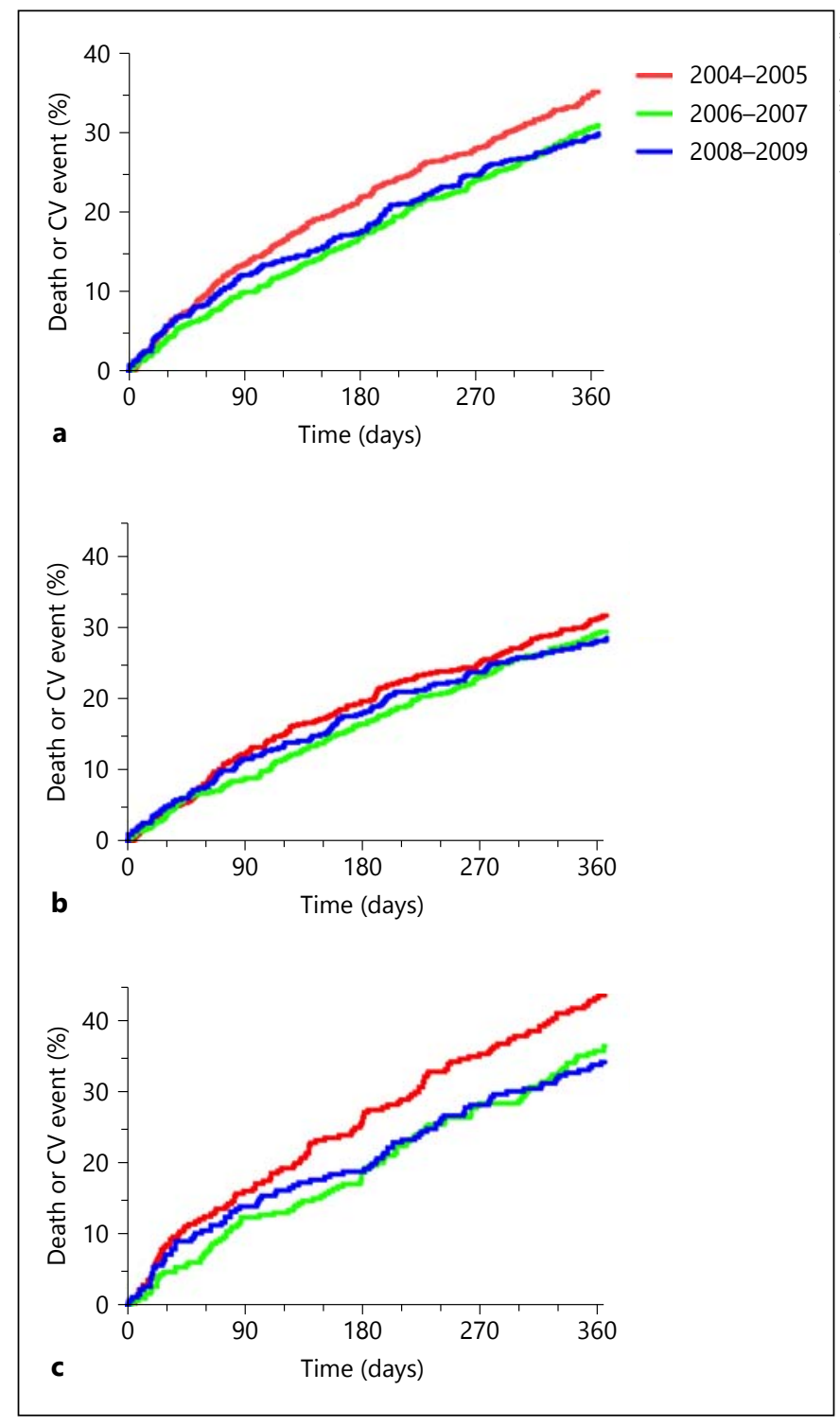

Fig. 1. Kaplan-Meier survival curve of composite endpoint (death or cardiovascular event) for elderly CKD patients who initiated dialysis by the year of VA insertion. a Full patient cohort. The cumulative incidence of death or cardiovascular event was substantially reduced from 2004-2005 to 2008-2009 (HR 0.83, 95\% CI 0.69-0.99; p = 0.04). b Age 70-80 years. The cumulative incidence of death or cardiovascular event was similar from 2004-2005 to 2008-2009 (HR 0.89, 95\% CI 0.71-1.12; $\mathrm{p}=0.33)$. $\mathrm{c}$ Age $>80$. The cumulative incidence of death or cardiovascular event was substantially reduced from 2004-2005 to $2008-2009$ (HR $0.74,95 \%$ CI $0.56-0.97$; $\mathrm{p}=0.03$ ).

sharp decrease in cardiovascular death among ESRD patients in the United States during the same time period [12]. Specifically, according to the USRDS, unadjusted cardiovascular mortality rates among prevalent ESRD patients declined from 81.9 to 64.1 deaths per 1,000 patient years at risk for the overall population and from 2004 to 2008 and from 198.9 to 152.5 for patients 75 years and older [12]. In our study, we observed a $17 \%$ reduction in risk of death or CV events in the first year of dialysis. In fact, our study suggests that the most significant improvement in the incidence of death or cardiovascular event in the first year of hemodialysis decreased substantially from 2004-2005 to 2008-2009 in the most elderly patients, that is those patients age $>80$.

We also postulated that better medical care in the current study population would be reflected in more frequent outpatient physician visits (with nephrologists or other physicians) or less frequent hospitalizations after undergoing VA surgery. This hypothesis was not supported by our data. However, our database does not include more specific medical interventions prescribed during these visits or hospitalizations (e.g. blood pressure control, use of ACE inhibitors or ARBs, diabetic control, prescription of statins).

A less likely explanation for the improvement of cardiovascular comorbidities among elderly CKD patients undergoing predialysis access surgery is that nephrologists are preferentially referring for predialysis access surgery to those patients with less cardiovascular morbidity. Testing this hypothesis would require a comparison of cardiovascular comorbidity in elderly CKD patients with and without predialysis access surgery. Unfortunately, the database we utilized lacks information about kidney function. As a consequence, we did not have a suitable control group. Furthermore, supportive care may be another issue for not considering preemptive access in elderly advanced CKD patients. In recent years, there has been a concerted emphasis on patient-centered and shared decision making for our elderly advanced CKD patients [13-15], which may impact our thought process when considering preemptive VA placement in this group. In other words, because dialysis may not confer survival benefit in certain groups of elderly patients with comorbid conditions, excluding them from consideration for preemptive VA placement is a reasonable approach.

A number of previous studies have reported that patients with advanced CKD are significantly more likely to die than to reach ESRD and initiate dialysis during follow-up after a VA surgery [16-18]. The likelihood of dying before reaching ESRD and not initiating dialysis is particularly high in elderly patients with CKD, and still higher in those with substantial cardiovascular comorbidity [16]. However, the more likely a patient is to die before reaching ESRD and not in need of dialysis, the 
more compelling the justification for withholding predialysis access surgery. If elderly CKD patients are progressively having less cardiovascular comorbidities, it may be that a larger proportion should appropriately be considered for predialysis access surgery, as they are less likely to die before progressing to the need for hemodialysis.

A major strength of this study is the use of a nationally representative random sample of elderly patients with advanced CKD. This allows one to generalize the findings with a high degree of confidence to individual medical centers. Our study also has several limitations. First, we do not have information on the total number of elderly patients potentially eligible for predialysis access surgery, and so we cannot examine temporal changes in CVD for patients not selected for VA surgery. Second, we do not have documentation of the reason that a particular elderly patient with CKD was not referred for predialysis access surgery. Thus, we can only infer that the nephrologist or surgeon deemed a given patient to be a poor candidate for predialysis access surgery. However, there may be alternative reasons, such as patient refusal to undergo access surgery prior to starting dialysis. In the first 2 reasons discussed above, selection bias may be a possible explanation for improved level of cardiovascular comorbidities in elderly patients receiving preemptive permanent access. However, data from the National Heart, Lung, and Blood Institute have shown a steady decline in age-adjusted death rates for cardiovascular disease in the general medical population in the United States during the time period of our cohort [19]. While the data do not specifically pertain to that of elderly CKD patients, we may also be seeing a similar trend in this population. Finally, our data are limited to a period of 6 years, and we do not know whether the trends described in this study began prior to 2004 or continued after 2009. If, in fact, the progressive improvements in cardiovascular comorbidities continued after 2009, as was the case among the general US population $[4,19]$, this lends enhanced credence to our conclusion that more elderly patients should be deemed eligible for VA surgery before dialysis.

\section{Conclusions}

In conclusion, the observations in this study show that among elderly patients with advanced CKD patients undergoing predialysis VA placement, the cardiovascular comorbidities has decreased progressively from 2004 to 2009. Consequently, these patients are now less likely to die before dialysis initiation, more likely to survive with- out ESRD, and equally likely to start HD within 2 years of access surgery. Because they are healthier, these patients are also less likely to have cardiovascular events after starting dialysis. These insights should be translated into more thoughtful consideration of which elderly patients should undergo predialysis access surgery. Thus, our observations from this study suggest that for a select group of elderly CKD patients without significant cardiovascular comorbidities, increased placement of predialysis VA may be warranted.

\section{Disclaimer}

The data reported in this study have been supplied by the USRDS. The interpretation and reporting of these data are the responsibility of the authors, and in no way should be construed as the official policy or interpretation of the US government.

\section{Support and Financial Disclosures}

Dr. T. Lee is supported by an American Society of Nephrology Carl W. Gottschalk Scholar Grant, University of Alabama at Birmingham Nephrology Research Center Anderson Innovation Award, and University of Alabama at Birmingham Center for Clinical and Translational Science Multidisciplinary Pilot Award (1UL1TR001417-01). Dr. T. Lee is a consultant for Proteon Therapeutics.

Dr. M. Allon is supported by grant 1R21DK104248-01A1 from the National Institute of Diabetes, Digestive and Kidney Diseases (NIDDK). He is also a consultant for CorMedix and Gore.

Dr. M. Thamer is supported by grant 1R21DK104248-01A1 from the NIDDK. Dr. M. Thamer is a consultant for Protoen Therapeutics. Dr. Q. Zhang and Ms. Y. Zhang are supported by grant 1R21DK104248-01A1 from the NIDDK and R03-HS-022931 from the Agency for Healthcare Research and Quality and have no financial disclosures to report.

\section{References}

1 Lee T, Thamer M, Zhang Y, Zhang Q, Allon M: Outcomes of elderly patients after predialysis vascular access creation. J Am Soc Nephrol 2015;26:3133-3140.

2 Sarnak MJ, Levey AS, Schoolwerth AC, Coresh J, Culleton B, Hamm LL, McCullough PA, Kasiske BL, Kelepouris E, Klag MJ, Parfrey P, Pfeffer M, Raij L, Spinosa DJ, Wilson PW; American Heart Association Councils on Kidney in Cardiovascular Disease, High Blood Pressure Research, Clinical Cardiology, and Epidemiology and Prevention: Kidney disease as a risk factor for development of cardiovascular disease: a statement from the American heart association councils on kidney in cardiovascular disease, high blood pressure research, clinical cardiology, and epidemiology and prevention. Circulation 2003;108:2154-2169. 
3 Tonelli M, Wiebe N, Culleton B, House A, Rabbat C, Fok M, McAlister F, Garg AX: Chronic kidney disease and mortality risk: a systematic review. J Am Soc Nephrol 2006;17:2034-2047.

4 Mozaffarian D, Benjamin EJ, Go AS, Arnett DK, Blaha MJ, Cushman M, de Ferranti S, Despres JP, Fullerton HJ, Howard VJ, Huffman MD, Judd SE, Kissela BM, Lackland DT, Lichtman JH, Lisabeth LD, Liu S, Mackey RH, Matchar DB, McGuire DK, Mohler ER 3rd, Moy CS, Muntner P, Mussolino ME, Nasir K, Neumar RW, Nichol G, Palaniappan L, Pandey DK, Reeves MJ, Rodriguez CJ, Sorlie PD, Stein J, Towfighi A, Turan TN, Virani SS, Willey JZ, Woo D, Yeh RW, Turner MB; American Heart Association Statistics Committee and Stroke Statistics Subcommittee: Heart disease and stroke statistics - 2015 update: a report from the American heart association. Circulation 2015;131:e29-e322.

5 Collins AJ, Foley RN, Herzog C, Chavers BM, Gilbertson D, Ishani A, Kasiske BL, Liu J, Mau LW, McBean M, Murray A, St Peter W, Guo H, Li Q, Li S, Li S, Peng Y, Qiu Y, Roberts T, Skeans M, Snyder J, Solid C, Wang C, Weinhandl E, Zaun D, Arko C, Chen SC, Dalleska F, Daniels F, Dunning S, Ebben J, Frazier E, Hanzlik C, Johnson R, Sheets D, Wang X, Forrest B, Constantini E, Everson S, Eggers PW, Agodoa L: Excerpts from the US Renal Data System 2009 annual data report. Am J Kidney Dis 2010;55(1 suppl 1):S1-S420, A6-A7.

6 Oliver MJ, Quinn RR, Garg AX, Kim SJ, Wald $\mathrm{R}$, Paterson JM: Likelihood of starting dialysis after incident fistula creation. Clin J Am Soc Nephrol 2012;7:466-471.

7 Gullion CM, Keith DS, Nichols GA, Smith DH: Impact of comorbidities on mortality in managed care patients with CKD. Am J Kidney Dis 2006;48:212-220.

8 Stevens LA, Li S, Wang C, Huang C, Becker BN, Bomback AS, Brown WW, Burrows NR, Jurkovitz CT, McFarlane SI, Norris KC, Shlipak M, Whaley-Connell AT, Chen SC, Bakris GL, McCullough PA: Prevalence of $\mathrm{CKD}$ and comorbid illness in elderly patients in the United States: results from the kidney early evaluation program (KEEP). Am J Kidney Dis 2010;55(3 suppl 2):S23-S33.

9 Charlson ME, Pompei P, Ales KL, MacKenzie CR: A new method of classifying prognostic comorbidity in longitudinal studies: development and validation. J Chronic Dis 1987;40: 373-383.

10 Liu J, Huang Z, Gilbertson DT, Foley RN, Collins AJ: An improved comorbidity index for outcome analyses among dialysis patients. Kidney Int 2010;77:141-151.

11 Seliger SL: Comorbidity and confounding in end-stage renal disease. Kidney Int 2010;77: 83-85.

12 Collins AJ, Foley RN, Herzog C, Chavers B, Gilbertson D, Ishani A, Kasiske B, Liu J, Mau LW, McBean M, Murray A, St Peter W, Guo H, Gustafson S, Li Q, Li S, Li S, Peng Y, Qiu Y, Roberts T, Skeans M, Snyder J, Solid C, Wang C, Weinhandl E, Zaun D, Arko C, Chen SC, Dalleska F, Daniels F, Dunning S, Ebben J, Frazier E, Hanzlik C, Johnson R, Sheets D, Wang X, Forrest B, Constantini E, Everson S, Eggers P, Agodoa L: US Renal Data System 2010 annual data report. Am J Kidney Dis 2011;57(1 suppl 1):A8, e1-e526.

13 O'Hare AM, Armistead N, Schrag WL, Diamond L, Moss AH: Patient-centered care: an opportunity to accomplish the 'Three Aims' of the national quality strategy in the Medicare ESRD program. Clin J Am Soc Nephrol 2014;9:2189-2194.

14 Vandecasteele SJ, Kurella Tamura M: A patient-centered vision of care for ESRD: dialysis as a bridging treatment or as a final destination? J Am Soc Nephrol 2014;25:16471651.

15 Drew DA, Lok CE: Strategies for planning the optimal dialysis access for an individual patient. Curr Opin Nephrol Hypertens 2014;23: 314-320.

16 Collins AJ, Li S, Gilbertson DT, Liu J, Chen SC, Herzog CA: Chronic kidney disease and cardiovascular disease in the Medicare population. Kidney Int Suppl 2003;87:S24-S31.

17 Dalrymple LS, Katz R, Kestenbaum B, Shlipak MG, Sarnak MJ, Stehman-Breen C, Seliger S, Siscovick D, Newman AB, Fried L: Chronic kidney disease and the risk of end-stage renal disease versus death. J Gen Intern Med 2011; 26:379-385.

18 Collins AJ, Foley RN, Herzog C, Chavers B, Gilbertson D, Ishani A, Kasiske B, Liu J, Mau LW, McBean M, Murray A, St Peter W, Guo H, Li Q, Li S, Li S, Peng Y, Qiu Y, Roberts T, Skeans M, Snyder J, Solid C, Wang C, Weinhandl E, Zaun D, Arko C, Chen SC, Dalleska F, Daniels F, Dunning S, Ebben J, Frazier E, Hanzlik C, Johnson R, Sheets D, Wang X, Forrest B, Constantini E, Everson S, Eggers P, Agodoa L: United States Renal Data System 2008 annual data report. Am J Kidney Dis 2009;53(suppl):vi-vii, S8-S374.

19 National Institute of Health, National Heart, Lung, and Blood Institute: Morbidity and Mortality: 2012 Chart Book on Cardiovascular, Lung, and Blood Diseases, 2012 